\title{
PSICODELIA, HUMOR E MILITÂNCIA: OS COLETIVOS DE MULHERES QUADRINISTAS NO COMIX UNDERGROUND NORTE AMERICANO
}

\author{
PSICODELIA, HUMOR AND MILITANCY: THE COLLECTIVES OF \\ FEMALE COMIC ARTISTS IN THE NORTH AMERICAN COMIX UNDERGROUND
}

\section{RESUMO}

Atualmente muitas mulheres vem se destacando como autoras de histórias em quadrinhos, embora ainda em número menor do que em relação aos homens, podemos observar trabalhos bastante significativos e cada vez mais autoras produzindo. Isso se dá em especial pelas redes de apoio construídas por elas, estratégia utilizada desde há muito tempo para forjar seus próprios espaços de publicação. Neste artigo perpassaremos por algumas das primeiras estratégias de inserção das autoras de quadrinhos. Em especial, quando no bojo da contracultura norte-americana surgem os primeiros coletivos de mulheres quadrinistas: as obras It Aint' Me Babe (1970) e Wimmenscomix (1972-1992), TitsECClits (1972-1987). Observaremos como através da articulação em revistas produzidas apenas por mulheres, foi possível que houvesse uma organização enquanto quadrinistas, uma abertura de espaços para as futuras autoras e uma produção de obras originais - os comix underground pela perspectiva feminina.

Palavras-chave: Quadrinistas. Coletivos. Comix. Feminismo. Arte. Contracultura.

\begin{abstract}
Currentlymanywomen have come to stand out as comic book authors, although still in smaller numbers than in relation to men, we can observe quite significant works and more and more authors producing. This is especially true of the support networks they have built, a long-standing strategy to forge their own publishing spaces. In this article, we will go through some of the first strategies of insertion of women authors of comics. In particular, when in the bulge of the American counterculture the first collectives of women authors of comics. In particular, when the first collectives of women authors of comics emerge in the midst of the American counterculture: It Aint 'Me Babe (1970), Wimmenscomix (1972-1992), Tits \& Clits (1972-1987). We will observe how through articulation in magazines produced only by women, it was possible that there was an organization as comic artists, an opening of spaces for the future authors and a production of original works - the comix underground by the feminine perspective.
\end{abstract}

Keywords: Female comic artists. Collective. Comix. Feminism. Art. Underground.

Talita S. Medeiros

Universidade Federal de Santa Catarina (UFSC) - Brasil. E-mail: medeirostali@gmail.com 
Nas décadas de 1960/70, a atmosfera revolucionária da contracultura norte americana transformou a cultura da época e engendrou novos elementos como o comix underground, quadrinhos produzidos de forma quase artesanal e distribuídos de maneira independente, em pequena escala e sem grandes pretensões comerciais. Não passavam de brochuras impressas em papel tosco, mas que acabaram por modificar elementos narrativos e estruturais da indústria dos quadrinhos. Essas obras tornaram-se mais uma expressão de seu tempo e alçaram a categoria de ícones, seus precursores, como Robert Crumb e Gilbert Shelton. Autores que viram nos comix uma ferramenta para contestar os valores morais e o modo de vida tradicional, brincar com o universo hippie, no qual estavam inseridos, e sem pudores expor suas mais polêmicas fantasias sexuais. Significativo, é que nos comix underground podemos vislumbrar uma forte característica vigente nos quadrinhos até os dias atuais: a predominância masculina em sua produção e distribuição. Também podemos observar outra característica recorrente, o fato de que as mulheres, mesmo estando em menor número, sempre procuraram conquistar seu lugar, algumas se destacando consideravelmente. No que se refere a busca de espaço através de uma articulação coletiva as autoras de comix underground são pioneiras, abrindo importantes caminhos para as mulheres quadrinistas. O movimento underground norte americano, embora tenha fornecido um contexto em muitos sentidos excludente para as mulheres, é também muito importante para a história das autoras, pois é aí que surgem os primeiros coletivos de mulheres quadrinistas, como It Ain't Me Babe (1970), Wimmen'sComix (1972-1992), Tits\&Clits (1972-1987), dentre outros. Neste artigo, discutiremos como de forma totalmente aventureira e experimental autoras como Trina Robbins, Sharon Rudhal, Lee Marrs, ShelbyShampson, Roberta Gregory, Aline Kominsky, Barb Brown, CarynLeschen, Diane Noomin, Dori Seda, DotBucher, Joyce Farmer, KathrynLeMieux, KrystineKryttre, Lee Binswanger, Leslie Ewing, Melinda Gebbie, Michelle Brand, Terry Richards, LynChevli, dentre outras, se organizaram e forjaram para si espaços de produção e distribuição. As mulheres interessadas nos comix se articularam e se agruparam, buscando estratégias de inserção que derivaram em uma pequena, porém, bastante interessante produção artística.

Diversos movimentos sociais surgiram na efervescência dos anos de 1960. Após a intervenção norte americana no Vietnã em 1963, iniciam-se várias manifestações pela retirada das tropas americanas dos países asiáticos, e um movimento contracultural jovem tomou corpo. Surgem então, o que JosettTrat (2009) chama de os 'novos' movimentos sociais, manifestações como os movimentos jovens por Direitos Civis, pela igualdade racial, liberdade sexual dos gays e lésbicas, libertação das mulheres e os movimentos pacifistas. Segundo Trat (2009), esses 'novos' movimentos sociais se expressaram a partir de outros vetores da identidade social além do de classe, pois sua ênfase estava nas dimensões subjetivas e nas dimensões culturais da política, evidenciando "o enfraquecimento ou a dissipação da política de classe, bem como das organizações políticas de massa associadas a ela, e sua fragmentação em vários e distintos movimentos sociais" (Hall, 1992: 290). 
O termo "contracultura" foi definido pelo historiador Theodore Roszak (1968), como uma "cultura de oposição política", sobretudo contra a tecnocracia e o complexo industrial-militar do pós-guerra. A contracultura jovem dos anos 1960 foi influenciada por movimentos contraculturais anteriores, como a geração beatnik, contudo, trazia também, elementos próprios, como a busca por uma "existência autêntica" (Barros, 2002: 153). Como destaca Patrícia Barros (2002), "essa busca levou a geração contracultural da década de sessenta a ampliar seu conceito de política, estendendo-a ao corpo, ao comportamento dos indivíduos, à questão sexual" (Barros, 2002: 153). Ressalta que, para tal, como principais referências tinham "a psicanálise, o existencialismo e as filosofias orientalistas, base da chamada "nova consciência"' (Barros, 2002: 153).

A contracultura do período se expressa também em diversos produtos culturais, e "teve um encontro bastante feliz e fecundo com os quadrinhos" (Patati\& Braga, 2006: 110). Como salienta Carlos Patati e Flávio Braga (2006), a revolução contracultural introduz elementos inovadores nos quadrinhos, tanto no que se refere às temáticas abordadas, quanto a linguagem utilizada. Aumentando os dispositivos narrativos de que o meio dispunha até então. Além de ter impacto direto sobre a forma de distribuição habitual deste produto e sobre a questão da autoria nos quadrinhos.

Figura 1

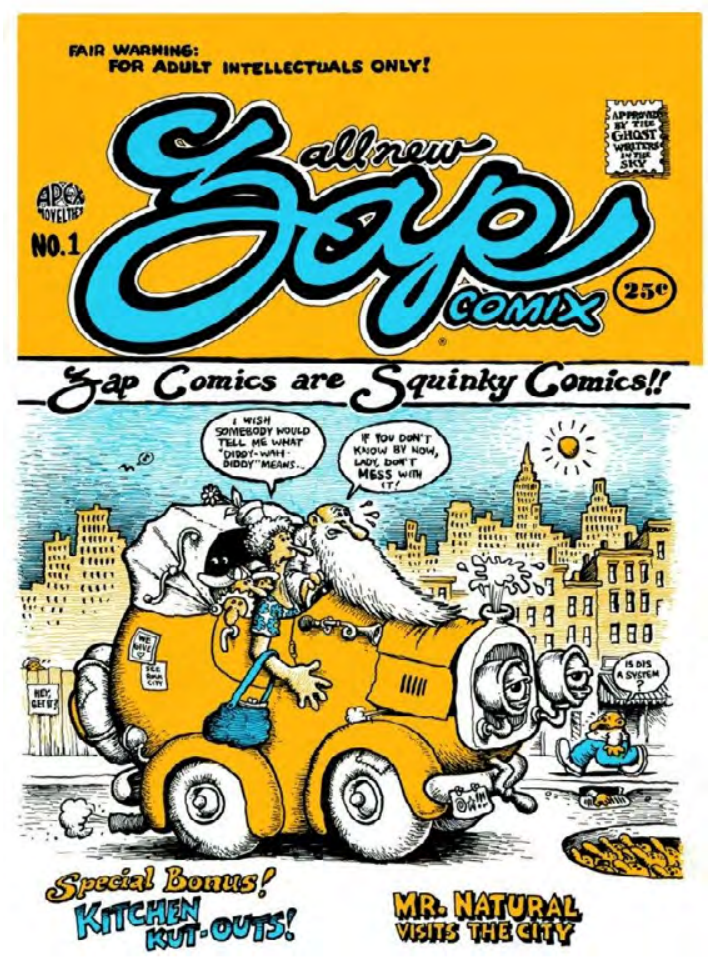

Isso se dá, quando em meados da década de sessenta, "paralelamente as publicações das grandes editoras, começou a circular uma produção de histórias

1 Costuma-se datar a contracultura a partir da beat generation, com o recital de poesia da sixgallery em 1955 ou a publicação de "on the road" de Kerouac, 1957. 
em quadrinhos independentes, underground, cujos personagens faziam sexo, fumavam maconha ou tomavam exageradas doses de LSD" (Oliveira, 2007: 34). De estilo satírico e provocativo, estes novos quadrinhos tornaram-se conhecidos como comix para separá-los dos quadrinhos tradicionais e a fim de enfatizar o " $\mathrm{x}$ " remetendo a $x$-rated(pornográfico/ obsceno). Segundo o historiador da arte Santiago Garcia (2010), o barateamento dos processos de impressão facilitou o surgimento da chamada imprensa underground, a partir de $1965^{2}$. O autor ressalta ainda "que outra via de publicação para os futuros desenhistas underground foram as revistas de humor universitárias" (Garcia, 2010: 142). Contudo, pontua, que "o verdadeiro comix underground" só iria se consagrar na segunda metade da década, momento no qual, Robert Crumb lança em São Francisco o ZapComix(1968). Logo, formou-se um movimento dos comix underground que aglutinou diversos autores interessados em produzir esse tipo de quadrinho, e assim, no final dos anos sessenta, a cidade de São Francisco, no Estado norte americano da Califórnia, estava convertida na 'Meca' desse quadrinho underground que se desenvolvia no seio de uma borbulhante cena contracultural.

Na figura 1 está a capa do primeiro ZapComix, na qual vemos um dos mais conhecidos personagens de Crumb, Mr. Natural, um sarcástico guru, e sua mulher chegando a cidade. Segundo Garcia (2010), o que Crumb trazia de novo eram os temas da geração hippie, "o momento encarnado em seu personagem". Crumb satirizava ainda as estruturas do quadrinho tradicional, como por exemplo, ao imprimir no canto superior direito de seu comix um selo de aprovação, no qual se lê: "aprovado por escritores fantasmas no céu". Isso se dá, pois, embora esteja vinculado a contracultura, o comix underground é em grande medida, também uma reação ao ComicsCode, o qual, regulamentava a indústria dos quadrinhos desde 1954, vetando a circulação de obras que contivessem representações de violência, sexo, drogas, ou qualquer conteúdo socialmente progressivo. Nem todas as editoras se submeteram a essa disciplina, entretanto, como consequência seus produtos não levavam o selo de aprovação na capa e ficavam impedidos de se inserir no sistema de distribuição. Como resultado, nos anos que se seguiram a criação do Code, as tentativas de se fazer um quadrinho adulto foram sufocadas, vigorando as produções voltadas para o público juvenil e adequadas a valores morais. Como pontua Garcia (2010), sem espaço para renovação nas editoras comerciais, esta acabou surgindo doscomix underground, a partir desse momento, pela primeira vez, existiam não só quadrinhos para adultos, mas exclusivamente para adultos.

2 Os autores de comix encontraram as primeiras oportunidades em jornais de tendência esquerdista, como o Los Angeles Free Press (de Los Angeles, Califórnia), o Berkeley Barb (Berkeley, California) e o The East Village Other (Nova York, N.Y.), os quais vinculavam artigos, resenhas e letras de músicas e quadrinhos que tratavam de assuntos da contracultura. 


\section{Figura 2}

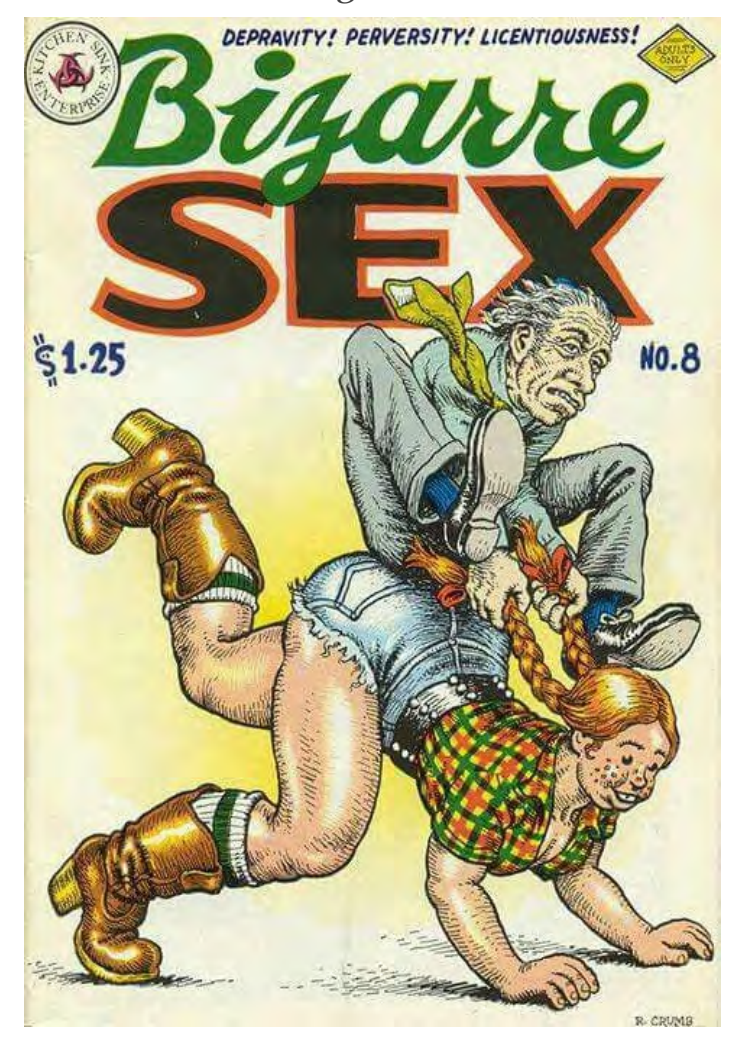

Os comix undergrounds foram um "sucesso e fenômeno artístico e cultural, reflexo de uma era” (Moya, 1993: 188). No momento em que o espírito libertário chega aos quadrinhos, desencadeia-se uma verdadeira revolução, cuja liberdade está em seu cerne. Claro que, ao não se submeter a aprovação do ComicsCode, os comix tiveram "vários conflitos com a lei e denúncias de obscenidade” (Garcia, 2010: 144), porém, estavam livres da censura editorial. $\mathrm{O}$ fato de que eram auto editados, ou editados por editoras underground 3 (administradas por companheiros geracionais dos autores que compartilhavam as mesmas ideias, princípios e objetivos), fez com que os autores não precisassem responder as diretrizes editoriais, nem se adequar a linhas homogêneas de interesses comerciais, ou ainda a questão de serem produzidos e distribuídos a margem da indústria, sem grande expectativa comercial - foram fatores que somados, levaram a uma enorme liberdade criativa.

Mas o que essa liberdade nova e sem precedentes significou para um grupo de talentosos e rebeldes artistas composto apenas por homens? Bem, dentre outras coisas, resultou em uma grande vazão de fantasias. O sexo era temática recorrente nos quadrinhos underground. Eram comuns histórias cheias de fetiches masculinos, nas quais, não raro, as mulheres apareciam em situações de submissão e de exploração sexual. "O sexo, a violência, a paródia ou a homenagem a gêneros do passado como o horror e a ficção científica, ou ainda, a mistura de todos esses elementos, haviam

3 Surgiram "editoras" underground, algumas importantes (Last Gasp, Rip-off Press, Print Mint, Kitchen Sink, Renegate Press). 
dominado a maioria dos comix underground, quase sempre com a justificativa do humor como último horizonte" (Garcia, 2010: 154).

Na figura 2 temos a capa da revista Bizarre Sex $n \div 8$, ilustrada por Robert Crumb. Acima do título lê-se as palavras Depravity! Perversity! Licentiousness!,antecipando o que o leitor iria encontrar ao aventurar-se em suas histórias. Em seu desenho, elementos recorrentes do trabalho de Crumb: um auto retrato como uma figura franzina, sobrepujando uma figura feminina corpulenta, com pernas e glúteos exageradamente grandes. Embora, sexo e violência, frequentemente combinados e resultando em fantasias que vitimizam a mulher, apareça em muitas obras de do autor, sendo "uma das especialidades que fez Crumb ser mais conhecido, de fato" (Garcia, 2010: 151), esse tipo de representação era habitual nos comix.

Os comix underground eram obviamente destinados ao público masculino, mas, embora poucas mulheres estivessem ativamente produzindo quadrinhos neste período, muitas estavam envolvidas no underground como um todo. É o caso de Trina Robbins, artista visual que mudou-se para São Francisco, impelida pela excitação dos novos movimentos sociais. Robbins, que viria a ser uma das figuras mais importantes do comix underground de mulheres, pontua que o que viu ao se aproximar da cena dos quadrinhos underground, não foi nada animador. Além de ser um ambiente masculino, os autores "incluíam violência gráfica contra as mulheres em seus comix, retratando essa violência com humor" (Robbins, 2013: s/p),

(...) na maioria dos círculos de São Francisco era quase regra para os cartunistas homens do underground incluir a violência contra a mulher em seus comix, e retratar essa violência com humor. Para esses caras, e para muitos de seus leitores do sexo masculino, cenas de estupro gráfico eram o máximo, cabeças decapitadas de mulheres rolando nos corredores (Robbins, 2013: s/p).

Para ela um contexto irritante, no qual cenas de violência contra a mulher eram retratadas como algo chistoso e "as mulheres que consideravam que as cenas de estupro, tortura e assassinatos não eram engraçados, eram tidas como sem senso de humor" (Robbins, 2013: s/p). Neste contexto, quando algumas mulheres tentam produzir quadrinhos underground, mais do que enfrentar os 'caretas' da sociedade, depararam-se também com embates com os homens quadrinistasunderground que já gozavam de um certo sucesso em meados dos anos 1970, momento no qual as mulheres procuravam abrir espaço nesse universo. Trina Robbins já envolvida com as artes visuais desde a muito tempo, pontua que seu interesse por quadrinhos despertou ao ver um comix no jornal undergroundThe East Village Other, que se distanciava agudamente dos quadrinhos comerciais, "eram sobre hippies e não super heróis" (Robbins, 2016: s/p). Instigada pela diferente produção dos comix underground, decidiu que queria fazê-los. Contudo, ao aproximar-se da cena de produção do comix, percebeu que se tratava de um grupo bastante fechado. Melinda Gebbie, também uma destacada quadrinistaunderground diz que "era uma espécie de 'Clube 
do Bolinha'. Nós tivemos que montar nosso pequeno acampamento perto do clube dos meninos, mas não muito perto ou eles viriam bater na nossa porta e atirar papel higiênico em chamas pela janela. Era essa mentalidade" (Gebbie, 2010: s/p).

Embora tenham encontrado espaço de publicação nos jornais underground, segundo as autoras havia um posicionamento de exclusão por parte dos quadrinistas, na medida em que não eram chamadas para colaborar nas revistas em circulação, ou antologias produzidas pelos autores do underground da Califórnia dos anos de 1970. Acerca da primeira exposição de comix underground na livraria Peace EyeBookstore, organizada por Ed Sanders, Robbins comenta: "ele incluiu todos os caras e eu fiquei de fora”. Revela ainda outro posicionamento, o de ignorar a presença de mulheres no meio. "Os cartunistas do underground que me tratavam como se eu fosse invisível eu penso, que esperavam que eu FOSSE invisível” (Robbins, 2013: s/p).

Robbins estava envolvida com o movimento feminista e pontua que foi ao ler um artigo sobre a liberação das mulheres em um jornal underground, que relacionou as dificuldades encontradas para produzir seus quadrinhos com uma questão de relações de gênero. "Eu percebi que eu estava sendo excluída dessas coisas por ser mulher” (Robbins, 2013: s/p). É então que a autora decide, que uma organização por parte das mulheres quadrinistas seria necessária, assim, Robbins e mais algumas autoras como Lee Marrs, Meredith Kurtzman, Nancy Kalish 'Hurricane Nancy', se articulam e começam a produzir suas próprias revistas e a incentivar uma maior participação de mulheres no comix. Paul Gravett (2010) salienta que essas autoras desencadearam uma revolução dentro dos comix underground.

Dentro dos comix undergrounds é como se houvesse uma outra revolução, porque as mulheres não tinham espaço para participar da cena underground mais conhecida. Então é como se tivesse formado um microcosmo de mulheres que começaram a se auto editar no interior daquele movimento contracultural, é como se houvesse um outro movimento de contracultura dentro do movimento de contracultura mais amplo - os coletivos de quadrinhos feitos por mulheres (Gravett, 2010: s/p.).

\section{Os Coletivos de Mulheres Quadrinistas no underground}

Os coletivos de quadrinhos feitos por mulheres surgem quando dois importantes movimentos se encontram, o feminismo e os comix underground. Dois universos que mesclam suas linguagens e princípios para produzir obras que misturam arte e política e marcam para sempre a participação das mulheres nos quadrinhos.

Como pontua a ativista Fran Beal, "haviam muitos movimentos de mudança social acontecendo em meados de 1960, o que levou ao movimento de mulheres. Eles deram origem à consciência das mulheres de uma necessidade de operar em condições 
de igualdade" (Beal, 2014: s/p). O feminismo, entretanto é bem anterior a isso, como ressalta Elizabeth Garber (1991), não se trata de um conjunto fixo de princípios ou uma única posição ou abordagem, mas uma filosofia variada que continua evoluindo ${ }^{4}$. Nos Estados Unidos, o feminismo se organiza como um movimento coletivo de luta de mulheres, quando entre 1966 e 1971, irrompe o expressivo movimento conhecido como WomansMovimentLiberation 5 . O ponto alto desse período do feminismo é a importância que as questões que acontecem em âmbito privado têm. Carol Hanish num discurso em 1969 proferiu as assertivas que se tornaria símbolo do movimento e norteariam o projeto "o pessoal é político" que viria a ser emblemático do movimento feminista da segunda década do século XX. Hanish afirma que: "Nossos problemas pessoais são problemas políticos, para os quais não há solução pessoal"; "Pode haver apenas uma ação coletiva para uma solução coletiva”. Hanish ao fazer tais afirmações traz às discussões políticas, questões que até então eram tratadas como do âmbito do privado, questões com as quais "não se deveria mexer". A partir dessa dissolução de fronteiras entre o privado e o político, quebra-se uma antiga dicotomia (as fronteiras entre o que é do âmbito público e o que é da esfera do privado) e amplia-se o alcance do político e do que deve ser 'assunto' de toda sociedade. As articulações feministas desse momento "partem do reconhecimento das mulheres de que as relações entre homens e mulheres não estão inscritas na natureza, e que existe a possibilidade de sua transformação" (Fougeyrollas-Schwebel, 2009: 144). Rompendo silêncios, "as mulheres notaram que elas compartilhavam os problemas que foram ignorados pelos homens" (Husson; Mathieu, 2016: 31).

\footnotetext{
4 N'GonéFall (2007) ao falar de seu contexto como mulher Africana, pontua que o feminismo não corresponde a um programa universalmente global, mas assume características distintas, nas suas manifestações locais, apesar das interdependências entre os dois planos. Assim, o feminismo passa por diferentes momentos e suas ações precisam ser entendidas dentro dos diferentes contextos sociais e processos históricos.

5 Períodotido comoa segunda onda do feminismo. A primeira onda (SéculoXIX-1950), éfrequentemente apresentada em torno das reivindicações do voto: de fato, é a respeito dessas questões que as ações mais espetaculares foram realizadas nos Estados Unidos e no conjunto dos países europeus (Cf. FougeyrollasSchwebel, 2009). A segunda onda (começa em 1960) e o foco passa da emancipação das mulheres, para a liberação das mulheres. Os movimentos feministas dos anos 70 não se fundam na única exigência de igualdade, mas no reconhecimento da impossibilidade social de fundar essa igualdade dentro de um sistema dominado pelos homens. A maior relevância trazida pela segunda onda feminista é o rompimento da dicotomia público/ privado. O feminismo não se ocupa mais apenas da esfera pública, mas de todas as esferas da vida das mulheres.
} 


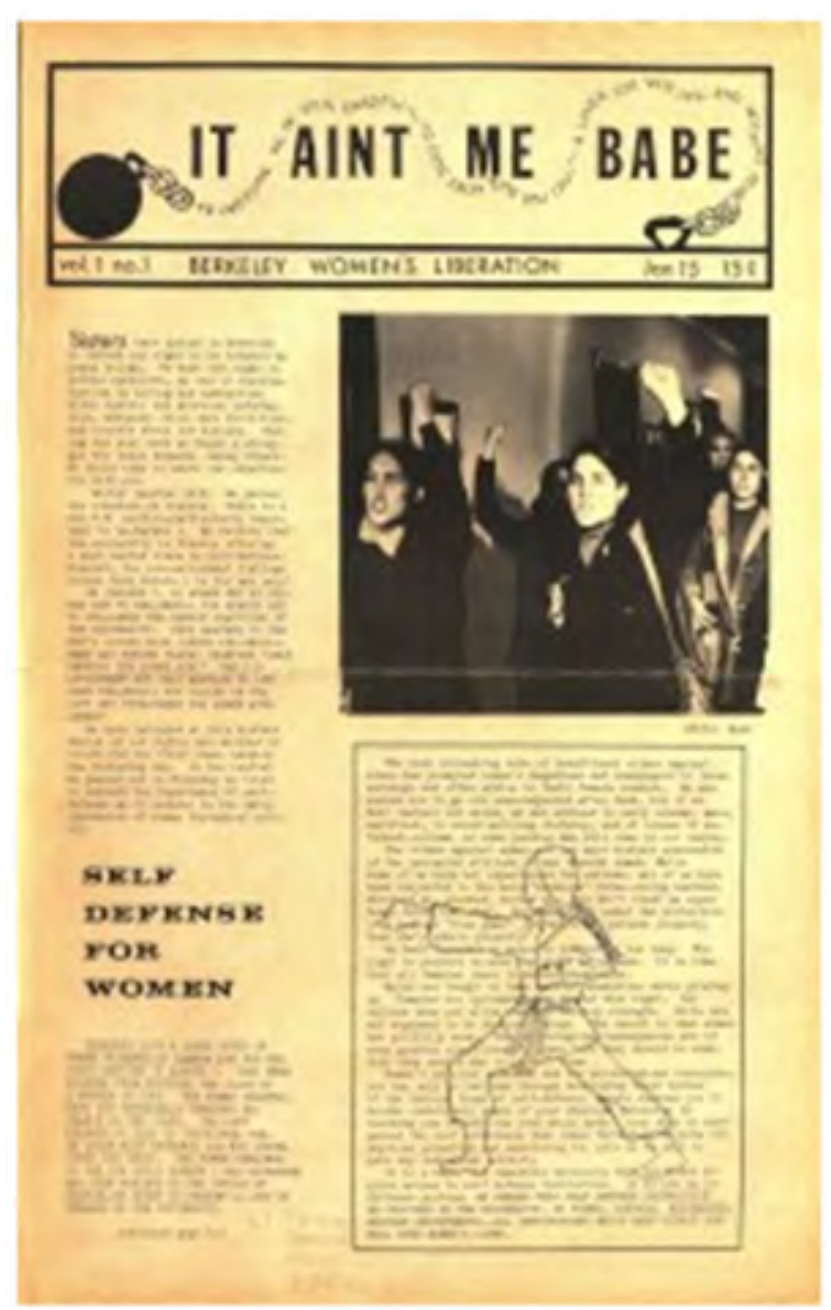

Dominique Fougeyrollas-Schwebel (2009) aponta que a luta por direitos das mulheres está relacionada também a observação da divergência entre os direitos legais e a sua prática real: "a reivindicação de direitos nasce do descompasso entre a afirmação dos princípios universais de igualdade e as realidades da divisão desigual dos poderes entre homens e mulheres" (Fougeyrollas-Schwebel, 2009: 144). "Nesse sentido, a reivindicação política do feminismo só pode emergir em relação a uma conceituação de direitos humanos universais" (Fougeyrollas-Schwebel, 2009: 144). A autora destaca que a demanda por direitos iguais abrange todo o conjunto das atividades sociais (direitos, família, direito do trabalho).

As reuniões feministas são fruto e também a causa de um contexto de inquietação das mulheres. Em circulação livros como The femininemystique de Betty Friedan (1963) suscitam reflexões sobre a condição da mulher na sociedade, nessa obra Friedan expunha como a cultura pressionava a mulher a cumprir papéis que lhe eram impostos, negligenciando suas potencialidades. Em suas articulações, oWomansMovimentLiberationlança suas próprias publicações. As ativistas feministas tornaram-se extremamente produtivas, transmitindo as experiências e a urgência da libertação das mulheres através da escrita e da publicação. Surgem importantes 
livros como OurBodies, Ourselves, produzido pelo Boston Women's Health Collective; boletins informativos, como FirstYear Notes; zines como SpareRib, dentre outras publicações. Como destaca Margareth Rago (1998), é "na luta pela visibilidade da 'questão feminina', pela conquista e ampliação de seus direitos específicos, pelo fortalecimento da identidade da mulher, que nasce um contradiscursofeminista" (Rago, 1998:28), e as publicações do movimento ajudam a difundir e visibilizar esse contradiscurso.

Assim, as publicações do movimento tornam-se muito importantes. As organizações feministas começaram a desenvolver seus próprios jornais, alguns anos após o surgimento da imprensa underground em 1965. A imprensa feminista ajudou o movimento a nascer e se comunicar, em seu interior, e também com o mundo exterior. Os jornais feministas eram empreendimentos coletivos e uma forma de dar voz às mulheres dentro da nova esquerda. Continham muito de jornalismo pessoal e anedotas (como parte do projeto 'O pessoal é político').

\section{It Aint Me Babe Journal}

O It Aint Me Babe, é considerado o primeiro jornal feminista/de libertação da mulher norte americano. Iniciado pelo Berkeley Women'sLiberation em Berkeley, Califórnia, em 1970. O periódico foi uma entre muitas pequenas organizações e publicações que compunham o amplo movimento de libertação da mulher, que começaram paralelamente. Parte de um movimento maior, foi uma ação, dentre outras, que buscava colaborar com o movimento mais amplo.

A quadrinista Trina Robbins, diz que ao ver a primeira edição do jornal, pensou "eu não podia acreditar! Um jornal underground feminista!" (Robbins, 2013: $\mathrm{s} / \mathrm{p})$. A autora que já havia colaborado com alguns jornais underground, ligou então para a equipe do It Ain't Me Babe dizendo ser uma artista interessada em colaborar com o projeto. 
Figura 4

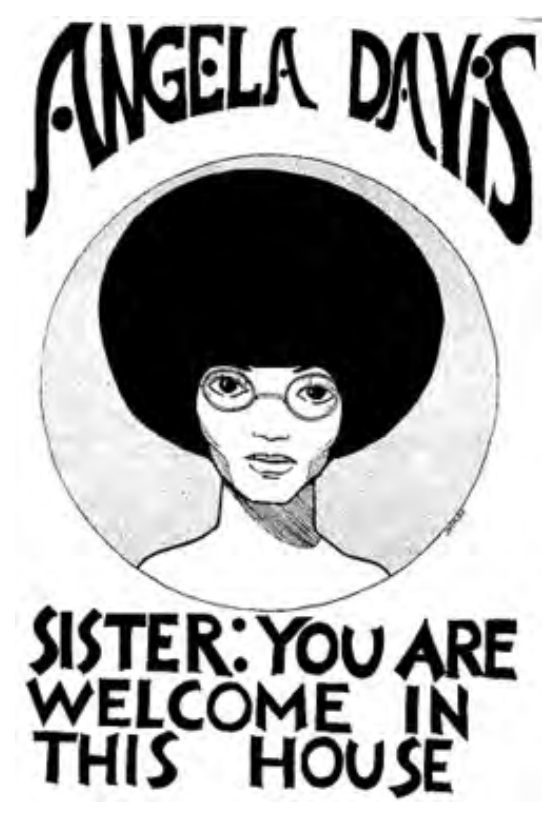

E assim, entrou na segunda edição, participando de todas as subsequentes. Desenhando capas frontais, capas traseiras e quadrinhos para o seu interior. Os trabalhos de Robbins para o jornal tratavam as questões feministas com humor - como nos frequentes quadrinhos em que satirizava situações cotidianas do relacionamento com seu marido mas também com um viés bastante político. É o caso de uma de suas capas, a qual traz um desenho retratando a ativista Angela Davis. Envolvida com o movimento dos Panteras Negras, Angela estava foragida por ser acusada pelo então governador da Califórnia, Ronald Reagen, "de três crimes puníveis com a sentença de morte - assassinato, sequestro e conspiração" (Davis, 2017:145). Davis foi a primeira mulher a entrar para a lista dos dez criminosos mais procurados pelo FBI. Na capa de Trina, a frase Sister: you are welcome in thishouse (Irmã: você é bem vinda nessa casa), foi pensada para que as mulheres feministas a colocassem em suas janelas, sinalizando assim, locais em que Angela poderia se esconder. A capa de Robbins desencadeou um pequeno movimento, logo as pessoas estavam fazendo cartazes com a imagem, e pendurando em suas janelas.

É notório o quanto o movimento feminista, os jornais feministas e os comix feministas têm elementos constituintes muito próximos, surgindo da necessidade de criação de seus próprios espaços. Sua experiência ao colaborar no jornal It Ain't Me Babejournal ofereceu a Trina Robbins um sistema de apoio que há muito lhe havia sido negado como mulher em um clube de homens no comix underground. Beneficiando-se dessa rede de apoio, Robbins decide publicar um livro de comix feminista, com trabalho apenas de artistas mulheres. A equipe do It Ain't Me Babe, veicula então, um chamado para mulheres artistas (Figura 5). Que dizia: "Apelo para artistas! It Ain't Me Babe precisa de sua ajuda. Qualquer mulher cartunista que esteja interessada em trabalhar em um comic book editado pelo It Ain't Me Babe. Por favor, nos contate o mais rápido possível”. 
Figura 5

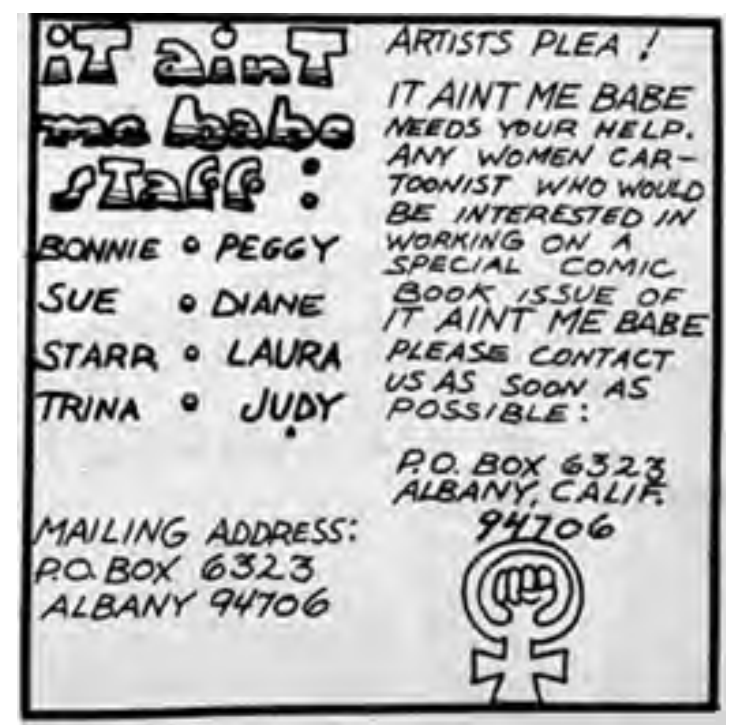

\section{It Ain't Me Babe Comix}

Os desenhos figuravam nos panfletos e jornais do movimento feminista, mas é com o It Ain't Me Babe comix, publicado em São Francisco em 1970, que surge o primeiro quadrinho coletivo de mulheres como uma obra completa.

Uma reflexão aqui se faz necessário, é importante pensarmos sobre o que significa para essas autoras começar a contar suas próprias histórias e se publicar num meio predominantemente masculino. Como veremos o separatismo cultural das mulheres foi usado como uma estratégia para uma busca de reconhecimento, com a defesa de muitas feministas da necessidade da criação de uma 'cultura feminina'.

Terre Barrett (2014), destaca que até o final da década de 1960, a maioria das artistas buscava "apagar o gênero" de sua arte a fim de competir em um mercado dominado pelos homens. Mas que nos anos 1960, a contracultura já não considera que a arte pudesse ser ideologicamente neutra, através do reconhecimento das feministas de que "o sistema da arte e a história da arte haviam institucionalizado o sexismo” (Barret, 2014:48). A crítica de arte, Linda Nochlin (1973), no início dos anos de 1970, questionou as causas da aparente inexistência das mulheres artistas na história, concluindo que tal ausência se deve mais a exclusão das mulheres das principais instâncias de formação de carreiras artísticas nos séculos XVIII e XIX, do que a uma falta 'natural' de talentos para as artes. Levando a uma reflexão sobre o lugar das mulheres na arte.

Desenvolve-se uma crítica feminista da arte e uma arte deliberadamente feminista, baseadas na concepção de que o gênero estava sendo subestimado pelos que acreditavam ser possível abordar e experimentar a arte com neutralidade. Assim, a arte feminista se propunha a aumentar a consciência, convidar ao diálogo e transformar a cultura. 
Contudo, a crítica de arte Lucy Lippard (1983) em retrocesso enfatiza que é importante lembrar que não se tratava de um grupo coeso, "um de nossos pontos fortes foi que jamais houve apenas um Feminismo único, unificado", "as definições de arte feminista sempre foram contestadas de modo apaixonado" (Lippard, 1983:40). Entretanto, a autora acredita que havia "uma cultura feminista que envolve um conjunto básico de valores comuns a socialistas, radicais, lésbicas e várias outras correntes de feministas", como "o aumento da conscientização, o convite ao diálogo e a cultura da transformação... a cultura feminista é um sistema de valores, uma estratégia revolucionária, um modo de vida" (Lippard, 1983:40).

Lippard (1980) enfatiza ainda, que a maior contribuição do feminismo vai para além de um combate estético ${ }^{6}$, tendo sido "muito complexa, subversiva e fundamentalmente política" (Lippard, 1980:362). "A insistência feminista de que o pessoal (e, portanto, a arte em si) é político, como uma séria inundação, interrompeu o fluxo do mainstream, enviando-o para centenas de afluentes" (Lippard, 1980:362). Arte e política estão entremeados neste contexto, e "talvez, o aspecto único da arte feminista que a torna mais estranha à noção dominante de arte, é que é impossível discuti-la sem se refletir as estruturas sociais que a apoiam e muitas vezes inspiram" (Lippard, 1980:363).

A quinta edição do jornal It Ain't Me Babe, trazia um artigo intitulado "Women ... Towards a New Culture", que estimulava a criação de uma cultura das mulheres como mais um instrumento da revolução feminista:

Vemos o desenvolvimento da cultura das mulheres como parte essencial da luta de libertação. A criação de uma ideologia cultural é uma forma de trabalho; Aceitamos produtos masculinos nessa área por muito tempo ... As culturas que nos cercam hoje na América, cujos princípios nós interiorizamos, foram criados pelos homens. É extremamente opressivo para nós operarmos em uma cultura onde os ideais são orientados para homens e as definições são controladas pelos homens. Nossa alternativa é clara; Devemos desenvolver uma nova cultura, novas imagens de nós mesmas e das forças que nos rodeiam. No entanto, a criação de uma cultura feminina não deve, de forma alguma, ser separada das lutas políticas das mulheres para a libertação ... Nossa cultura não pode ser a escultura de um enclave em que possamos suportar o status quo com mais facilidade - em vez disso, deve cristalizar os sonhos que irão fortalecer nossa rebelião.

6 A autora ressalta que se pode dizer que em torno de 1970 as mulheres artistas introduzem um elemento de emoção real e conteúdo biográfico para performance, bodyart, video, etc. E também que elas trouxeram para a arte o uso de formas das artes tidas como 'menores', como a costura, ou ainda que mudaram os padrões da pintura, usando elementos como a colagem. Porém, pontua que inevitavelmente, seria possível também citar homens que o fizeram. Para ela esses são fenômenos superficiais. Crendo ser inútil tentar definir uma contribuição formal específica feita pelo feminismo. Estando a sua verdadeira contribuição para o campo das artes na esfera política. 
Através de iniciativas como o It Aint me Babe Comix, o separatismo feminino surgiu como uma forte posição política para as feministas radicais, embora não fosse defendida por todos, como observa a estudiosa feminista Alice Echols (1989). O separatismo foi geralmente visto como uma "estratégia para alcançar a mudança social, e não como um fim em si mesmo" (Echols, 1989). Quando as vozes das mulheres foram suprimidas ou silenciadas na contracultura, as feministas radicais postularam que uma maneira de ser ouvida como mulheres era criar espaços exclusivos de livre expressão apenas de mulheres, até que as ideologias feministas estivessem mais absorvidas.

Assim, o feminismo chega nas mais diversas artes. Surgem poesias, músicas, peças de teatro, livros, quadrinhos, dentre outras expressões, desenvolvidos a partir dos ideais feministas. Submissões de trabalho foram feitas em resposta ao apelo do jornal It Ain't Me Babe. Porém, foi Trina Robbins a responsável por pesquisar mulheres que estavam produzindo quadrinhos, ou que se interessassem em fazê-lo e as convidou para participar da edição. Reuniu-se assim, um grupo de sete mulheres artistas $^{7}$, que com o apoio da equipe do jornal It Ain't Me Babe produziu o primeiro comix underground feminista, publicado em 1970 pela editora underground LastGasp. Uma brochura com 36 páginas, impresso em papel de jornal que tinha apenas as capas frontal e traseira coloridas e seu interior em preto e branco e era vendida por um dólar.

Seguindo o modelo de colaboração não hierárquico do jornal, as autoras contavam com toda liberdade criativa. Os temas são os mais variados, abordando assuntos como traição masculina, feminismo, a situação das mulheres no trabalho, psicodelia, amor, desigualdade social e assédio sexual ${ }^{8}$.

Eram em sua maioria histórias autoconclusivas que reflexionavam sobre as relações intimas com os homens e o abuso de poder em uma sociedade machista, ou sobre experiências autobiográficas marcadas por acontecimentos traumáticos como o abandono, o aborto, o estupro e os esforços pessoais para superar esses traumas (Merino, 2016: 26).

7 Trina Robbins, Lisa Lyons, Carole, Michele Brand (Wrightson), Bárbara "Willie" Mendes, Meredith Kutrzman e Nancy Kalish "Hurricane Nancy".

8 Esse comixé composto por treze histórias: VegetablesArise! de Meredith Kurtzman,Oma de Willy Mendes, Monday de Michele Brand, Lavender e I RememberTelluria de Trina Robbins, A Flower Fable de Lisa Lyons, Untitled de "Hurricane Nancy", Breaking Out de todo o coletivo, TiradeFunnies de Michele Brand e uma história sem título de Meredith Kurtzman. 


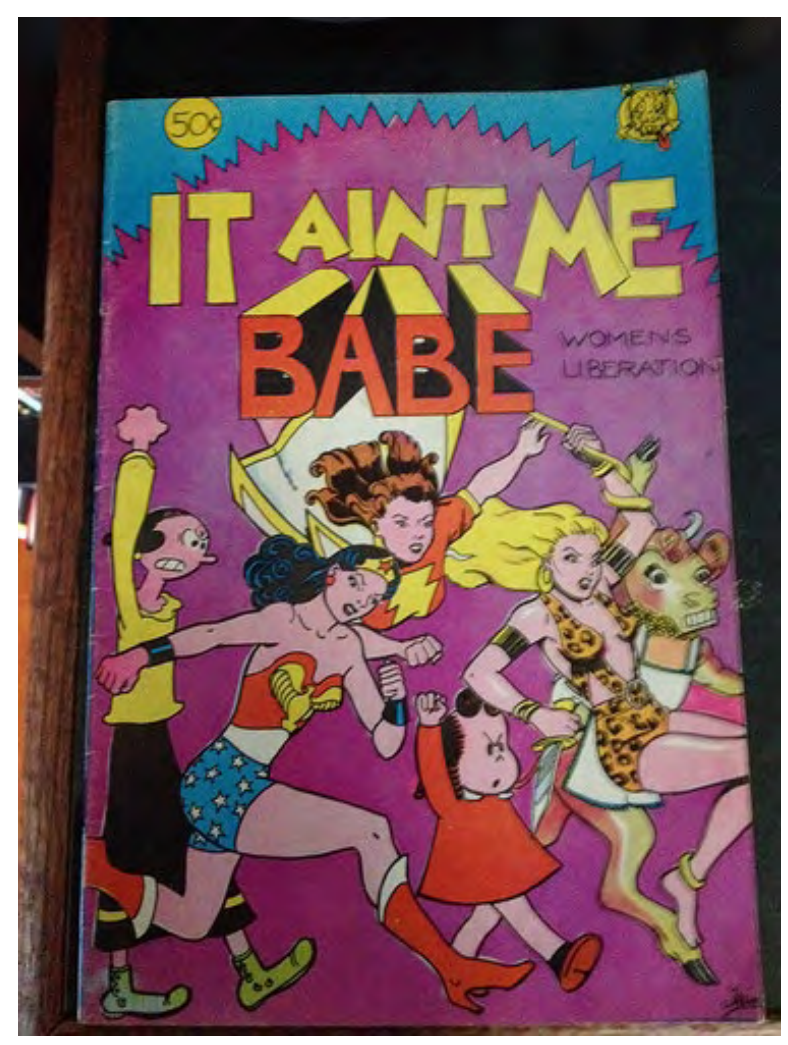

As mulheres desenhadas de forma hipersexualizada ou como ornamento de cena estão conscientemente ausentes das histórias. A capa desenhada por Robbins (Figura 6) ecoava o tema Womensliberation, trazendo algumas das principais personagens de quadrinhos mainstream: Olivia palito, Mulher Maravilha, Luluzinha, Sheena Rainha da selva e ElsietheBordenCow marchando juntas com punhos levantados e expressões de luta. Na contracapa uma provocação bem humorada diz que qualquer semelhança com personagens cômicos chauvinistas vivos ou mortos é estritamente admitida.

A história principal da edição, intitulada Breaking Out, segue a mesma linha, parodiando o quadrinho mainstream ${ }^{9}$ e suas personagens femininas. O roteiro da história é atribuído a todo o coletivo, ou seja, a todas as sete mulheres envolvidas nesta edição, e os desenhos são de Carole. A história subverte o papel original das personagens do quadrinho mainstream, na medida em que Petúnia Pig, Luluzinha, Betty e Verônica, e Super Girl, saem dos papéis estabelecidos, se rebelam e se unem contra os personagens masculinos opressores. Abandonando os personagens masculinos e formando uma comunidade de mulheres. A arte é bastante cuidadosa, imitando o material de origem parodiado.

9 Mainstream é um termo originalmente inglês empregado como um conceito para se referir ao modelo de pensamento ou gosto de caráter popular e dominante. Seria algo como "corrente principal", ou "fluxo principal". É usualmente empregado no campo da arte nas mais diversas expressões, e define aquilo que é comum, usual, familiar, disponível ao público e que detenha laços comerciais. 


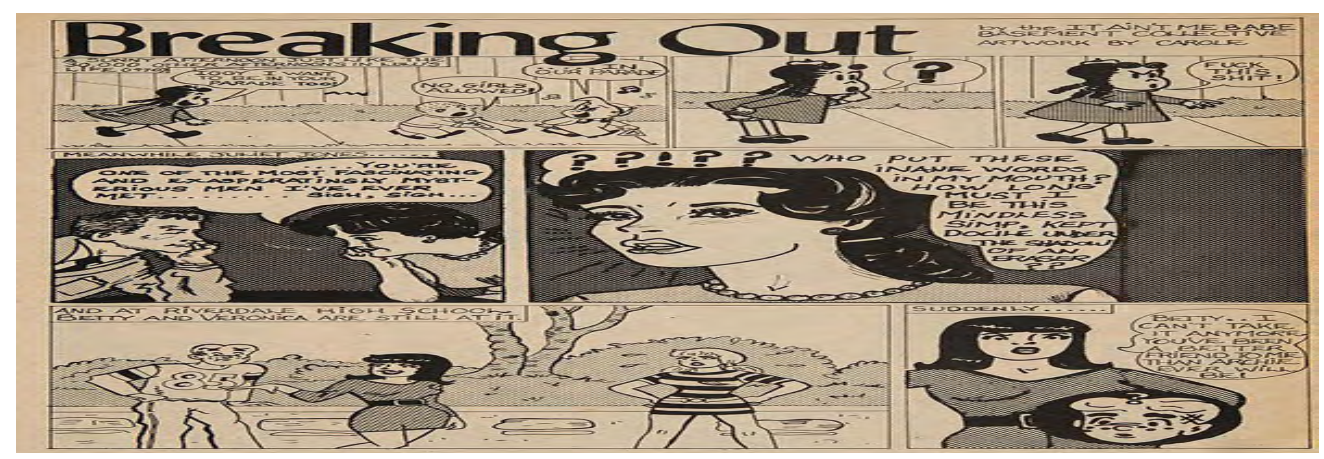

Na figura 7, trecho inicial da história, vemos a personagem Luluzinha que aparece pedindo para participar de uma marcha junto com os meninos, e recebendo a resposta de que garotas não são permitidas, porém, ao contrário da personagem no quadrinho mainstream, a Luluzinha underground responde sua interdição no clube dos meninos com um sonoro: Fuckthisshit!. Fato ocorrido após a bruxa Hazel espalhar a revolução feminista por todo o mundo.

Na história, as personagens, assim como, as mulheres do WomensLiberation, reúnem-se em grupos de discussão, para conversar sobre suas experiências pessoais, o que produz como reação uma conscientização e organização das mulheres, que vão às ruas reivindicar seus direitos civis e reparações sociais. Em determinado momento, vão para as ruas e numa das placas segurada por uma mulher em protesto na frente a uma escola, se lê: "Nós queremos aulas de história das mulheres". Em outro momento se vê a personagem Super Girl usando seus poderes não mais para ajudar o Super Homem, mas para libertar as mulheres da prisão. E por fim, as mulheres libertas e conscientes formam seu próprio clube, no qual homens não são permitidos, invertendo a lógica da história original.

Figura 8

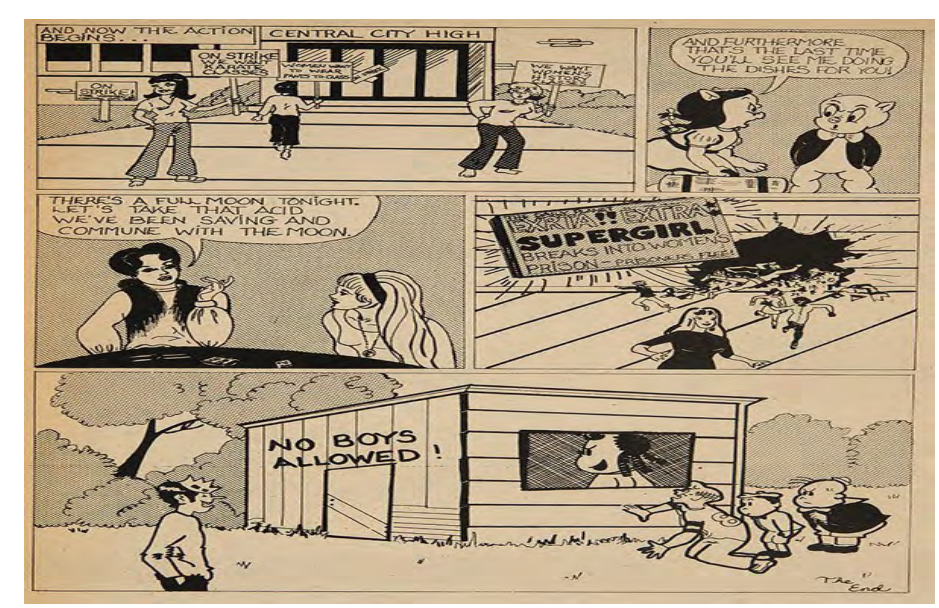

O It Ain't Me Babe abriu um importante caminho para as quadrinistas, inaugurando os trabalhos coletivos de quadrinhos de mulheres. Na perspectiva do que hoje se entende por Artivismo, a qual engloba expressões artísticas que se 
originam do desejo de provocar ou explicar uma causa, insere-se na busca feminista por "uma arte que reflita a consciência política do que significa ser uma mulher na cultura patriarcal" (Hammond, 1980: s/p). Além de inaugurar todo o movimento docomix underground feminino.

\section{Wimmen'scomix- a mais proeminente antologia de quadrinhos de mulheres}

A Wimmen'sComix, foi uma importante publicação coletiva de autoras de quadrinhos que surge a partir da experiência do It Ain't Me Babe Comix. Essas duas publicações são responsáveis por trazer a percepção de gênero para os quadrinhos. $\mathrm{O}$ modo de organização da Wimmen's se aproximava da estrutura dos grupos feministas, assim como, as histórias publicadas nas várias edições da revistatambémpossuíam uma perspectiva feminista.Assim, esses quadrinhos feitos por mulheres mesmo ainda que sem preparo ou sofisticação foram muito importantes, em especial pela inserção de temas até então não abordados. "Se a rebeldia dos autores undergrounds masculinos parecia derivar em escandalosas travessuras adolescentes, os comics gays e de mulheres introduziram uma consciência política mais rigorosa” (Garcia, 2010:151).

O comixIt Ain't Me Babe teve uma boa recepção, ganhando uma reedição. Logo Ron Turner, responsável pela editora undergroundLastGasp a qual havia veiculado a obra, vendo a boa aceitação, decidiu que gostaria de publicar outras obras do gênero. Surge assim o Wimmen'scomix, com dezessete edições, produzidas ao longo de vinte anos (de 1972 a 1992), sendo uma das primeiras e a mais longa antologia de quadrinhos de mulheres.

Trina Robbins optou por não encabeçar o projeto, assim, a função de cooptar artistas interessadas para participar do comix passou então para Patrícia Moodian, a autora que já a havia publicado alguns de seus trabalhos pela LastGasp, ficou com a editoração do primeiro volume de Wimmen'sComix. Formando, somada a Robbins e mais oito quadrinistas (Michelle Brand, Lee Marrs, LoraFontain, Sharon Rudall, ShelbyShampson, Aline Kominsky, Karen Mare Haskell, Janet Wolfe Stanley), o grupo que depois viria a ser conhecido como as 'mães fundadoras' do Wimmen'scomix ${ }^{10}$.

O grupo do Wimmen'sComixera composto por muitas mulheres envolvidas no movimento feminista, o que levou a um modo de organização muito próxima das do Women'sliberationmovement. "Talvez por causa de nossos antecedentes políticos ou talvez porque éramos mulheres, o coletivo Wimmen'sComix tinha métodos diferentes dos undergrounds masculinos desde o início" (Robbins, 2013: s/p). O Wimmen's

10 Destas autoras apenas Trina Robbins e Michele Brand foram colaboradoras também da edição do It Aint Me Babe Comix (1970). 
possuía um esquema de produção coletiva não hierárquica ${ }^{11}$, lançando mão de uma editoria rotativa e por vezes sendo coeditado por duas mulheres.

Talvez em parte, por sua experiência e dificuldades na cena do comix underground mais ampla, as mulheres procuravam ser o mais eram inclusivas possível, abrindo as submissões para todo tipo de trabalho, ainda que fosse de uma autora sem experiência alguma. Já que havia tão poucas mulheres na arte dos quadrinhos na época, uma das intenções do coletivo Wimmen'sComix era incentivar novas artistas a se envolverem. "Muitas mulheres que enviavam o material para nós nunca tinham desenhado um quadrinho antes e era evidente" (Robbins, 2016:9). "Mas nós estávamos mais interessadas em dar às mulheres uma voz do que em como elas poderiam usar o lápis e a tinta profissionalmente" (Robbins, 2016:9).

Embora o grupo de quadrinistas do Wimmen's não soubesse disso até ver a obra a venda nas head shops ${ }^{12}$, algumas semanas antes do lançamento de sua primeira edição, em 1972, duas mulheres do Sul da Califórnia, Joyce Farmer e Lynn Chevely (pseudônimo Chin Lively) também haviam reagindo ao sexismo do underground, e produzido seu próprio título, o Tits\&Clits, que contaria com sete volumes, publicados entre 1972 e 1987. "Eu ainda fico espantada com a sincronicidade de dois grupos de mulheres californianas, em lados opostos do Estado, decidindo ao mesmo tempo produzir um quadrinho do ponto de vista das mulheres. Isso era algo na água?" (Robbins, 2016:10).

Contudo, as duas produções embora sejam antologias de comixde mulheres (no sentido em que são conjuntos de diversas obras de autoras mulheres) diferem em muitos sentidos. Enquanto o surgimento do Wimmen's estava ligado aos jornais feministas do início da década de 1970 através do It Ain't Me Babe,TitsEClits surge da iniciativa de LynChevely. Chevely e o marido eram proprietários da livraria Fahrenheit 451, em Los Angeles, por meio do qual ela veio a ter contato com os comix underground, aspirando então, produzir um quadrinho de mulheres, uniu-se a Joyce Farmer - que viria a ser sua coeditora por toda a duração da revista - e começaram a produção de um quadrinho sexual de mulheres. Acerca do nome da revista, Chevely pontua: “Um dia nós estávamos sentados lá, desenhando, e ela gritou, 'Tits\&Clits!' E eu quase caí do meu banquinho. Eu sabia que era perfeito" (Chevely apud Meier, 2017:s/p). O nome era uma provocação ao titsandass, frequentemente usado em revistas masculinas. Fundamentalmente diferente, a revista de Farmer e Chevely não contava com uma estrutura coletiva e com a ideologia democrática subjacente do Wimmen's. Após dois volumes, as editoras resolveram abrir espaços para submissões de outras artistas, porém, segundo Samantha Meier (2017), essa foi uma maneira

11 Os grupos de fala eram muito valorizados na maioria dos grupos feministas, além do incentivo à formas de organização antiautoritárias, privilegiando as formas mais espontâneas de manifestação, e recusando toda organização hierárquica (Cf. Fougeyrollas-Schwebel, 2009:146). Seguindo essa linha, além de optar por uma editoração rotativa, para que nenhuma mulher pudesse se impor sobre as outras, no Wimmen'scomix, todas as colaboradoras avaliavam todos os trabalhos submetidos e davam seu feedback.

12 "Lojas de vendas de parafernália hippie" (Garcia, 2010:147) nas quais os comix costumavam ser vendidos. 
de viabilizar que as revistas fossem publicadas com mais frequência, tendo em vista que com uma equipe de apenas duas pessoas, Farmer e Chevely, conseguiam veicular apenas um comix ao ano. Era uma decisão possivelmente mais prática do que motivada ideologicamente.

Os volumes seguiam o modelo formal dos outros comix underground. A primeira edição do Titsera uma brochura de 32 páginas de conteúdo preto e branco e uma capa frontal e traseira em cores. A grande diferença era o fato de que Titstratavase de um comix auto editado. Isso se deu, pois Chevely e Farmer acabaram montando sua editora, a NannyGoatProductions, para viabilizar as edições. A NannyGoat conseguiu colocar seu trabalho em circulação através das conexões da livraria de Chevely, a qual conhecia autores docomix underground em Los Angeles. A partir da segunda edição fizeram uma parceria com Ron Turner de LastGasp para melhorar a distribuição da revista. No entanto, outras editoras, como a Print Mint-ainda que underground - inicialmente hesitaram em participar de TitsEClits, por considerá-lo muito obsceno. Para Farmer e Chevely, publicar um livro que era tão censurável era um ato radical de desafio contra o que as mulheres deveriam estar fazendo na época. Todavia, investindo seu próprio dinheiro na produção e considerando que cada cópia era vendida por US \$ 0,75 a US \$ 1,50, as autoras nunca tiveram retorno financeiro.

Embora o sexo estivesse presente também na Wimmen's, a diferença é que este não era essencialmente seu projeto editorial. Já a intenção da Tits era discutir a sexualidade feminina. TitsEClits, como um quadrinho de sexo produzido por mulheres, causou "um grande alvoroço dentro e além da comunidadedoscomix. De acordo com a Farmer, TitsEClits causaram desconforto às pessoas e, portanto, não foram amplamente lidas ou distribuídas" (Meier, 2017:s/p). Joyce Farmer acredita que "era controverso porque era sexo do ponto de vista de uma mulher, o corpo de uma mulher do ponto de vista de uma mulher" (Farmer apud Meier, 2014:s/p). TitsEClits rompe significativamente a fronteira privado / público, mergulhando profundamente no domínio do pessoal (Meier, 2017:s/p).

Outras obras surgiram com esse viés, contudo, curiosamente, embora um dos motes da contracultura fosse a liberdade sexual, a sexualidade feminina e suas fantasias não foram assim tão bem recebidas. Numa resposta à sua maneira à autores como Robert Crumb, que não raro colocavam mulheres em situações submissas em suas histórias, Melinda Gebbie relata que criou para a revista "WetSatin" (1976) uma história em que a personagem principal era uma mulher que mantinha os homens escravos em seu porão. "Foi um troco irritado ao tipo de misoginia impensada que existia nos quadrinhos masculinos", e que era minimizada pelos quadrinistasunderground dizendo: "Esse é só o tipo de quadrinhos que os homens estão fazendo” (Gebbie, 2010:s/p). E, quando uma mulher fez igual, disseram: ‘Ó, meu Deus, a cultura está se despedaçando!”, ironiza. (Gebbie, 2010:s/p).

Várias revistas de autoras mulheres surgem na década de 1970, inspiradas ou a partir de desmembramentos da equipe de colaboradoras do Wimmen'sComix, É importante considerar que embora o Wimmen's fosse bastante inclusivo - assim como os grupos feministas - não eram um grupo homogêneo. Ainda que fossem mulheres 
se articulando enquanto grupo deautoras, se reunindo em revistas específicas para o público feminino, as mulheres inseridas no contexto do underground não formavam um grupo coeso. Surgiram de fato, diversas abordagens feministas que se deram de formas diferentes. E algumas divisões foram se consolidando ao longo dos anos. "As relações entre o grupo de mulheres artistas pioneiras do Wimmen'sComixfoi se polarizando por causa de visões divergentes que algumas estabelecem na hora de definir o underground e o feminismo" (Merino, 2016: 27). Algumas colaboradoras “(...) sentiram a necessidade de diferenciar-se do resto do grupo e queriam desenvolver suas próprias histórias" (Merino, 2016: 27). Diane Noomin e Aline Kominsky criaram em 1976 o TwistedSisterscom uma perspectiva feminista menos radical que o Wimmen's, Roberta Gregory e Mary Wings lançam respectivamente: DynamiteDamsels(1976) e Come out Comix (1977), produzindo histórias relativas a suas experiências como mulheres lésbicas.

Assim, vão surgindo muitas publicações a partir do caminho aberto pelo It Ain't me Babe e pelo Wimmen'sComix. Gregory nos presta um grande serviço, ao trazer na última página de DynamiteDamsels (Figura 9), o título das revistas em circulação em 1976, segundo ela "produzidas pelas mais talentosas mulheres do país", acompanhadas de uma pequena descrição dos temas encontrados em cada uma delas e de suas preços e local de venda.

Contudo, das revistas produzidas por autoras nesse período, o Wimmen'sComixacabou sendo a mais significativa - por abrir caminhos, por sua extensão, e por dar voz a autoras que viriam posteriormente a atingir grande destaque como quadrinistas mulheres. Roberta Gregory relembra que "eram os anos préinternet, então o lugar para ser vista era naWimmensComix” (Gregory,2016:s/p).

Figura 9

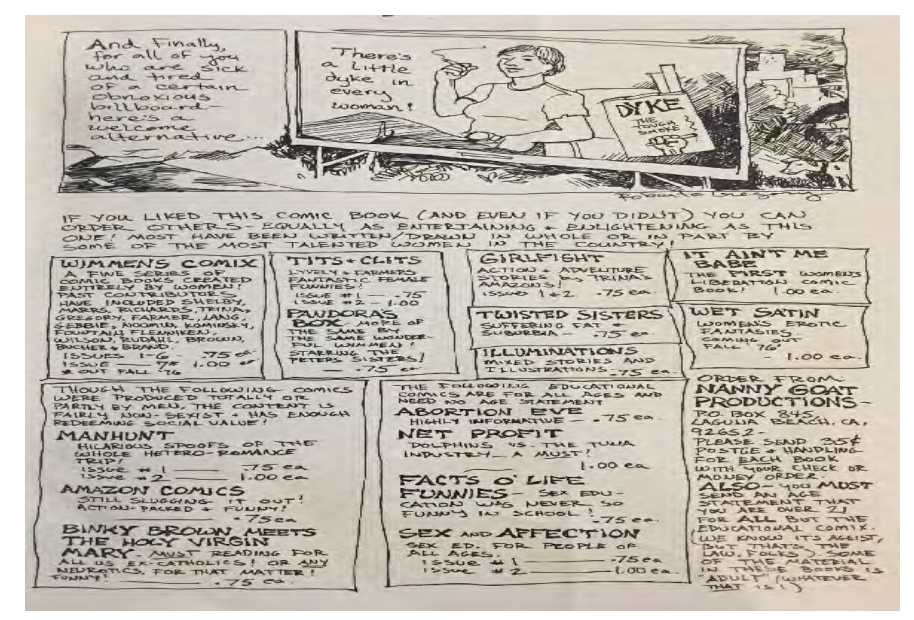

O Wimmen'sé uma publicação cujo nascimento está vinculado ao movimento feminista, contudo, embora num primeiro momento, a revistasignifique uma 'intervenção feminista’ no mundo misógino do underground desenvolvido até então, um caminho para as mulheres que eram outsiders no movimento de contracultura de onde emergiu os comix, o separatismo foi esmaecendo ao longo dos anos e as 
relações foram se modificando. Como pontua o sociólogo Paul Douglas Lopes (2006), as raízes feministas de Wimmen's não podem e não devem ser ignoradas, mas devem ser examinadas em sua total complexidade e não como uma intervenção ideologicamente uniforme. É importante considerarmos que se trata de 17 volumes, produzidos ao longo de vinte anos.

Em sua trajetória o Wimmen's foi publicado por três editoras: do primeiro ao décimo volume (1972-1985) pela LastGasp; os volumes onze, doze e treze (19871988), pela Renegate Press; e os quatro últimos números pela editora Rip off Press (1989-1992). Há, porém, um hiato de seis anos na produção, de 1977 a 1982. As autoras retornam com o Wimmen'sComix \#8 em 1983, mas então o cenário já se modificou. No início dos anos 1980, as head shops já não existiam mais. Conforme Trina Robbins (2013), o Wimmen'svendia bem nos tempos das head shops, contudo, com sua extinção, os quadrinhos passaram a ser vendidos principalmente em lojas especializadas de quadrinhos, "cujos proprietários ou administradores eram fãs de super heróis que preferiam vender os comics de super heróis" (Robbins, 2013:s/p). A edição final de Wimmen'sComix ocorreu em 1992. E o seu final teve menos a ver com a publicação em si, que estava melhorando constantemente em qualidade, e mais com a distribuição. Para Robbins (2016), esse foi o início do clube do bolinha de novo. "Não havia lugar para que nós fossemos encontradas exceto nas livrarias que vendem histórias em quadrinhos, frequentadas por garotos de 12 anos e homens de 30 que eram internamente meninos de 12 anos" (Robbins, 2013:s/p).

É importante pensar que o Wimmen's, assim como oscomix underground em geral, são datados. Afinal estavam vinculados a contracultura jovem da segunda metade do século XX. Assim, esse foi um dos elementos que contribuíram tanto para o seu surgimento, quanto para o fim. A contracultura explodiu, mas logo começou a perder vitalidade, como quase todos os movimentos contestatórios juvenis dos anos 1960. Os comix eram trabalhos que contavam com uma estética alternativa que representava uma ética alternativa; outro ponto relevante levantado por Santiago Garcia (2010) seria o fato de que em meados da década de 1970, ainda que a necessidade tenha impulsionado os principais expoentes do comix underground para a auto edição ou para editoras marginais, logo seu sucesso atraiu as grandes empresas (revistas de informação em geral, editoras literárias e produtores de Hollywood). O "underground já não estava à sombra, nas margens, nem na clandestinidade, estava exposto aos olhos do público consumidor junto com os demais produtos" (Garcia, 2010:167). Foi assimilado e começava a ser publicado pelas editoras tradicionais como a Marvel, que decidiu ampliar a oferta para além dos super heróis, publicando quadrinhos de artes marciais, fantasia heroica, terror e underground - como um gênero. Essa tendência anunciava a chegada de uma nova época na publicação não infantil, quadrinhos que rompiam com as limitações do ComicCode, porém, não com as dos gêneros tradicionais. $\mathrm{O}$ underground derivou então em um estilo que apenas sobrevivia nas páginas de poucos veteranos que seguiam ativos para título individual. Porém, nascia outro produto: o quadrinho alternativo. 


\section{A relevância dos coletivos underground para a posterior produção das mulheres nos quadrinhos}

No que se refere a produção feminina nos Estados Unidos, Ana Merino (2016) chama de as 'filhas do underground' autoras como Phoebe Gloeckner, Debbie Drechsler, Julie Doucet e Carol Lay, as quais vem desenvolvendo desde os anos 1990, a vertente autobiográfica intimista inaugurada pelas pioneiras do underground. "Herdeiras dessa linha intimista inaugurada primeiro pelo underground feminista" (Merino, 2016: 29), são artistas que "tocam em temas como o abuso infantil e o incesto, acrescentando qualidade estética e profissional gráfica à sordidez e ao sofrimento de seus relatos pessoais". Contudo, num contexto de maior profissionalização das mulheres quadrinistas, Merino pontua que as autoras do pós-underground "controlam tanto o discurso narrativo, quanto o gráfico, são estupendas desenhistas que dominam todos os níveis expressivos da arte sequencial” (Merino, 2016: 29).

$\mathrm{Na}$ esteira do que fizeram as quadrinistas dos coletivos undergrounds, em outras partes do globo, como no Brasil, as autoras continuam lançando mão da tríade arte, feminismo e humor para suscitar questões. $\mathrm{O}$ feminismo ainda ressoa, em sua terceira ... ou como defendido por muitos, quarta onda. Simone Pereira Schmidt (2015), em seu texto "O Feminismo, ainda", reflexiona acerca das respostas que o feminismo tem a nos oferecer no momento atual. E conclui que "sinalizam não somente para sua atualidade, mas para seu caráter de extrema necessidade frente aos riscos sempre recolocados de retrocesso e perda de territórios" (Schmidt, 2015: 293). A autora pontua que se mergulharmos em direção à radicalidade política e epistemológica que é constitutiva do feminismo, podemos entendê-lo como resposta contundente aos desafios do presente. "Mais do que necessidade, em última instância, o momento presente aponta para a urgência do feminismo, se considerarmos as profundas desigualdades com que não cessamos de nos deparar e a constante necessidade que temos de criar estratégias de enfrentamento" (Schmidt, 2015: 293). É o caso da personagem Olga, a sexóloga taradóloga,criada em 2009 pela quadrinistas Thaïs Gualberto. Olga é uma especialista em sexo, bastante direta em suas opiniões, como podemos constatar na figura $10^{13}$, em que um homem revela que seu casamento está em crise, pois, todos os dias sua mulher briga com ele por este não lavar a louça, Olga pergunta, porque então ele não lava, e numa expressão de seu machismo responde que lavar louça é "coisa de mulher" e Olga rebate de forma irônica perguntando se ao lavar a louça o homem corre o risco de perder seu órgão sexual masculino.

13 Embora tenha uma formação em Arte e Mídia - Universidade Federal de Campina Grande (UFCG/2010), tem um desenho bastante experimental, no qual podemos observar que não há uma intenção de se seguir formalidades estéticas para expressar seu pensamento, a autora faz uso de um traço infantil e pouco refinado, bem ao estilo dos comix dos anos 1970, onde a força maior residia na narrativa. 
Figura 10

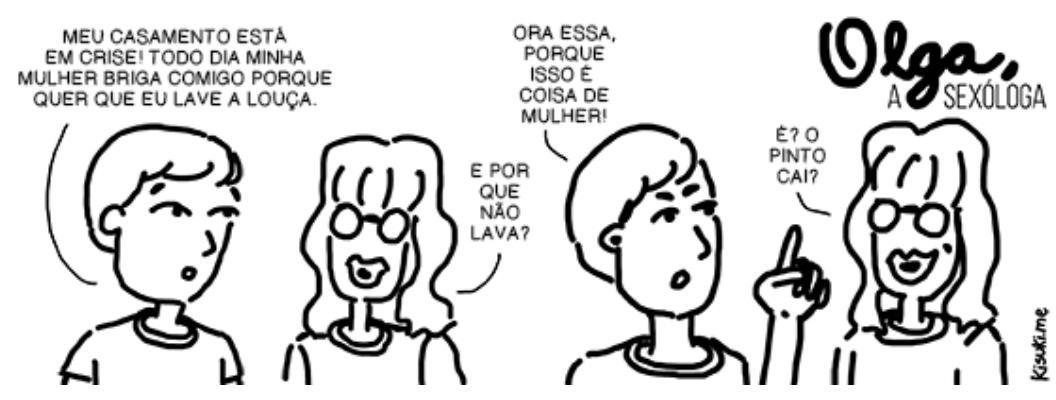

Os caminhos abertos pelas quadrinistas dos anos 1970 foram fundamentais para as quadrinistas contemporâneas. Tanto na abertura de espaços, quanto no encorajamento para a produção das mulheres artistas. Mas se nos anos 1970 um coletivo de mulheres quadrinistas foi uma atitude sem precedentes, atualmente eles são bastante recorrentes na produção das autoras.

As ações coletivas tem sido um recurso utilizado pelas quadrinistas, sendo bastante comum a organização em coletivos de mulheres quadrinistas. É o caso daRevista Inverna (2016), um projeto de publicação de quadrinhos de autoras mulheres, que tem como objetivo incentivar mulheres brasileiras a produzir seus próprios quadrinhos. Em seu primeiro volume, a revista reuniu autoras profissionais e iniciantes com estilos bastante diversos que produziram suas narrativas baseadas no tema 'Mulheres Brasileiras'. Em outros países também vem sendo realizados projetos semelhantes, é o caso das revistas Springs (Alemanha), Caniculadas (Espanha), Presentes(Espanha), Clitoris (Argentina), dentre outras, demonstrativas de como a organização das mulheres em coletivos surge como uma eficaz resposta as limitações a que elas estão submetidas "em uma profissão marcada por uma estrutura sistêmica criada por e para outros” (Mccausland; Berrocal, 2016: 07), assim como, da importância da construção de uma rede de apoio para as autoras, tanto no fomento da produção, quanto na visibilidade do que vem sendo produzido pelas quadrinistas.

Ao que parece, os espaços exclusivos para as autoras ainda são necessários. Todavia, assim como, o separatismo da arte feminista proposto nos anos 1970 não era um fim em si mesmo, tratando-se sobretudo de uma busca por uma mudança social, as articulações em revistas apenas de mulheres caminham num sentido da visibilidade e abertura de possibilidades. Uma busca e um encaminhamento para quenum próximo momento, os quadrinhos sejam reconhecidos/ apreciados pelas suas qualidades e não pelo gênero de seu autor.

\section{Considerações finais}

No que se refere a produção das autoras de histórias em quadrinhos, é notório a importância das redes de apoio construídas por elas como resposta às limitações a que estão submetidas. Essas redes viabilizaram a produção e a inserção das autoras 
no meio dos quadrinhos e são representativas do posicionamento de solidariedade e inclusão assumido em grande parte por elas. Nos quadrinhos underground os coletivos (uma reunião de indivíduos com interesses comuns, em busca de uma ação coletiva) foram a maneira das mulheres se organizarem e conseguirem publicar seus trabalhos, e tornaram-se fundamentais para que tivessem espaço de atuação. Esses coletivos de mulheres quadrinistas que se iniciaram na década de 1970 nos Estados Unidos, ou seja, as iniciativas de autoras e produtoras de quadrinhos que e se unem para desenvolver ou publicar uma obra, ou uma revista seriada, foram muito importantes para a inserção das autoras nesse campo artístico. A produção coletiva de obras como It Ain't Me Babe (1970), TitsEClits (1972-1987) e WimmensComix (1972-1992), mostram a força da ação coletiva e a importância de um grupo como instrumento catalisador. Através da construção de redes de apoio, as mulheres puderam se organizar enquanto quadrinistas, abrir espaços, produzir e publicar seus próprios quadrinhos.

\section{Referências Bibliográficas}

BARRETT, Terry. (2014). A Crítica de Arte: como entender o contemporâneo. 3 a edição. Porto Alegre: AMGH Editora LTDA.

BARROS, Patrícia Marcondes. (2002). "As concepções políticasda'esquerdapornográfica’porLuiz Carlos Maciel. Memória e Vida Social. Assis, São Paulo: EditoraUNESP. p.153-167.

BEAL, Fran. (2014).She's Beautiful When She's Angry.Documentário. Diretora: Mary Dore.Produtores:MaryDore\&NancyKennedy.SaltLakeCity:InternationalFilmCircuit. $92 \mathrm{~min}$.

CAMPOS, Rogério de. (2017). A Supercensura contra a turma dos quadrinhos. 2010. Disponível em:https://revistacult.uol.com.br/home/a-supercensura-contra-aturma-dos-quadrinhos/. Acesso em: 04 set.

CANICULADAS. Disponível em: http://caniculadas.blogspot.com/ Acesso em: 18 set. 2018.

CLITORIS. Disponível em: http://revistaclitoris.blogspot.com/2015/o4/clitoris-loscuatro-numeros-disponibles.html. Acesso em: 18 set. 2018.

CRUMB, Robert. (1968).All new Zap Comix. n. 1. São Francisco, Califórnia: Apex Novelties.

DAVIS, Angela. (2017). Mulheres, Cultura e Política. São Paulo: Boitempo. 
ECHOLS, Alice. (1989).Daring to be bad: Radical feminism in America, 1967-1975. Minneapolis: University of Minnesota Press.

FALL, N'Goné. (2007). “Creatinganareaof freedom: womenartistsfromAfrica”.Catálogo da exposição Global Feminisms. Brooklyn:Center for Feminist Art, Brooklyn Museum.

FOUGEYROLLAS-SCHWEBEL, Dominique. (2009). "Movimentos feministas". In: HIRATA, Helena et.al. (org.). Dicionário Crítico do Feminismo. São Paulo: Editora UNESP.

FRIEDAN, Betty. (1963). The femininemystique. Nova York: W. W. Norton.

GARCIA, Santiago. (2010). La Novela Gráfica. Bilbao: Astiberri Ediciones.

GARBER, Elizabeth. (1991). "ArtCriticism as Ideology". Journal of Social Theory in Art Education. n.11, p. 50-67.

GEBBIE, Melinda. (2010 ). “Entrevista”. G1. Rio de Janeiro. Disponível em: http:// feminismo.org.br/e-como-fazer-sexo-para-uma-multidao-diz-melinda-gebbie-dehq-co m-moore/ Acesso em: 03 set. 2017.

GRAVETT, Paul. (2010). Palestra Quadrinhos Ingleses. Rio ComiconInternational. Rio de Janeiro. Disponível em: http://www.youtube.com/ watch?v=O8e6uFDWaHg\&list=PL8C2E1D479A55F3Do\&index 1 Acesso em: 20 mar. 2015 .

GREGORY, Roberta. (1976).Dynamite Damsels. Long Beach, Califórnia: Nanny Goat Productions.

GREGORY, Roberta. (2016). Wimmen'sComixRetrospective. Museum of ComicandCartoonArt(MoCCA). ArtsFest2016,NewYork,NY. Disponível em: https:// www.youtube.com/watch?v=2ISQcTViEAA. Acesso em: 03 out. 2018.

HALL, Stuat. Cultural studies and its theoretical legacies.In:GROSSBERG,L.et.al. (eds.). (1992). Cultural Studies. New York: Routledge.

HAMMOND, Harmony. (1980). "HorseBlinders”. Heresies, n.9, p.45-47.

HANISCH, Carol. (1969). The PersonalisPolitical. Disponível em: http://carolhanisch. org/CHwritings/PIP.html Acessado em: 03 set. 2017.

HUSSON,AnneCharlotte\&MATHIEU,Thomas.(2016).LapetiteBédéthèquedesSavoirs: Le féminisme. En 7 slogans et citations. Bruxelas: Editora Le Lombard. 
INVERNA: Ficção gráfica brasileira de autoria feminina. (2016). Volume 1. Disponível em: https://tapas.io/episode/399224. Acessoem: 13 set. 2018.

IT AIN’T ME BABE. (1970). Berkeley, Califórnia: Last Gasp.

JOURNAL Cultural Correspondence. (1979). n.9. Chicago: Living Blues Collective.

LIPPARD, Lucy. (1980)."Sweeping Exchanges: The Contribution of Feminism to the Artofthe 1970s". ArtJournal. n. 1, p. 362-365.

LIPPARD, Lucy. (1983). "Artist/ Critc". Arts Magazine. n.59. p.40, nov.

LOPES, Paul Douglas. (2016). Demanding Respect: The Evolutionof the American Comic Book. Philadelphia: Temple University Press.

McCAUSLAND, Elisa \& BERROCAL, Carla. (2016). Presentes: autoras de tebeos de ayer y hoy.Madrid:AECID.

MEIER, Samanta. (2017). Tits\&Clits. Hoodedutilitarian. Disponível em: http://www. hoodedutilitarian.com/2014/o3/tits-clits/. Acesso em: o1 set.

MERINO, Ana. (2016). El eje feminino americano y laconsolidación de sus miradas. In: McCAUSLAND, Elisa \&BERROCAL, Carla. Presentes: autoras de tebeos de ayer y hoy. Madrid: AECID.

MOYA, Alvaro da. (1993). História da história em quadrinhos. 2 a edição.São Paulo: Editora Brasiliense.

NYBERG, Amy Kiste. (1998). Seal ofApproval: The History of the Comic Code. Jackson: University Press of Mississipi.

NOCHLIN, Linda. (1973). Why There Have Been no Gratests Women Artists? Art and Sexual Politics. 2a edição. New York: Macmilan Publishing Co.

NOGUEIRA, Maria Cláudia França (org.). (2014). As Periquitas. São Paulo: Editora KALACO.

OLIVEIRA, Selma Regina Nunes.(2007). Mulher ao quadrado: asrepresentaçõesfemininasnos quadrinhos norte-americanos: permanências $e$ ressonâncias (1895-199o) . Brasília: Editora Universidade de Brasília: Finatec. 
PATATI, Carlos \& BRAGA, Flávio. (2006). Almanaque dos Quadrinhos: 100 anos de uma mídia popular. Rio de Janeiro: Ediouro.

RAGO, Margareth. Epistemologia feminista, gênero e história. In: PEDRO, Joana Maria \& GROSSI, Miriam Pillar (org.). (1998). Masculino, feminino, plural: gênero na interdisciplinaridade. Florianópolis: Editora Mulheres.

RISCA.(2015). Memória e política das mulheres nos quadrinhos. Belo Horizonte: edição via financiamento coletivo.

ROBBINS, Trina. (2013). “Wimmen's Studies”.Labrys, étudesféministes/ estudosfeministas. vol. 23. jan.-jun.

ROBBINS, Trina. (2016). Introdução. In: The Complete Wimmen'sComix. Seattle: FantagraphicsBooks.

ROSZAK, Theodore. (1968). The Making of a Counter. Nova York: Anchor Books.

SCHMID, Simone Pereira. (2015). O Feminismo, ainda. In: FREITAG, Raquel MeisterKo\& SEVERO, Cristine Gorski (org.). Mulheres, Linguagem e Poder - Estudos de Gênero na Sociolinguística Brasileira. São Paulo: Blucher, p. 291-304.

SPRINGS.Disponível em:http://www.springmagazin.de/index.php?/ongoing/spring/ Acesso em: 18 set. 2018.

TITS \& CLITS. (1972). n.1. Long Beach, Califórnia: Nanny Goat Productions.

TITS \& CLITS. (1976). n.2. Long Beach, Califórnia: Nanny Goat Productions.

TITS \& CLITS. (1977). n.3. Long Beach, Califórnia: Nanny Goat Productions.

TITS \& CLITS. (1977). n.4. Berkeley, Califórnia: Last Gasp.

TITS \& CLITS. ( 1979). n.5. Berkeley, Califórnia: Last Gasp.

TITS \& CLITS. (1980). n.6. Berkeley, Califórnia: Last Gasp.

TITS \& CLITS. (1987). n.7. Berkeley, Califórnia: Last Gasp.

TRAT, Josett. (2009). Movimentos Sociais. In: HIRATA, Helena et.al. (org.). Dicionário Crítico do Feminismo. São Paulo: Editora UNESP.

WET SATIN: Women's Erotic Fantasies. (1976). n.1. Berkeley, Califórnia: Last Gasp. 
WIMMEN'S COMIX. (1972). n.1. Berkeley, Califórnia: Last Gasp. WIMMEN’S COMIX. (1973). n.2. Berkeley, Califórnia: Last Gasp. WIMMEN’S COMIX. (1973). n.3. Berkeley, Califórnia: Last Gasp. WIMMEN’S COMIX. (1974). n.4. Berkeley, Califórnia: Last Gasp. WIMMEN’S COMIX. (1975). n.5. Berkeley, Califórnia: Last Gasp. WIMMEN’S COMIX. (1975). n.6. Berkeley, Califórnia: Last Gasp. WIMMEN’S COMIX. (1976). n.7. Berkeley, Califórnia: Last Gasp. WIMMEN’S COMIX. (1983). n.8. Berkeley, Califórnia: Last Gasp. WIMMEN’S COMIX. (1984). n.9. Berkeley, Califórnia: Last Gasp. WIMMEN'S COMIX. (1985). n.10. Berkeley, Califórnia: Last Gasp. WIMMEN’S COMIX. (1987). n.11. Long Beach, Califórnia: Renegate Press. WIMMEN’S COMIX. (1987). n.12. Long Beach, Califórnia: Renegate Press. WIMMEN’S COMIX. (1988). n.13. Long Beach, Califórnia: Renegate Press. WIMMEN'S COMIX. (1989). n.14. Aubum, Califórnia: Rip off Press. WIMMEN’S COMIX. (1989). n.15. Aubum, Califórnia: Rip off Press. WIMMEN'S COMIX. (1990). n.16. Aubum, Califórnia: Rip off Press. WIMMIN’S COMIX. (1992). n.17. Aubum, Califórnia: Rip off Press. WINGS, Mary. (1977). Come out Comix. Portland, Oregon: Portlandswomensresource center.

Recebido: 15.08.2018

Aceito: 12.10 .2018 